\title{
Maintenance doses for clozapine
}

\author{
Bernadette Murphy, Colm Long and Carol Paton
}

\begin{abstract}
The Brttish National Formulary (BNF) entry for clozapine clearly distinguishes the treatment dose $(200-450 \mathrm{mg}$ daily, maximum $900 \mathrm{mg}$ ) from the maintenance dose $(150-300 \mathrm{mg}$ daily). We looked at 44 patients maintained on clozapine locally and found that 36 (82\%) recelved doses above the BNF guidelines. This has considerable cost implications. While it is atways good practice to maintain patients on the lowest possible dose of antipsychotic, the BNF guidellines are not based on objective outcome data, and should be treated cautiously.
\end{abstract}

Clozapine is an atypical antipsychotic drug which has been shown to be effective in up to two-thirds of patients with otherwise treatment resistant schizophrenia (Kane, 1992). Extrapyramidal side-effects (EPSEs) with clozapine are rare, and for this reason, it is also indicated in those patients who have developed intolerable motor side-effects with conventional neuroleptics. The major side-effect associated with clozapine is agranulocytosis and the associated compulsory haematological monitoring contributes to clozapine's high cost. While agranulocytosis is not dose related (Gerson \& Meltzer, 1992), other troublesome side-effects are likely to be. These include seizures (Devinsky et al, 1991), sedation. salivation, constipation (Lieberman \& Safferman. 1992) and weight gain (Paton \& Wolfson, 1996). Dose related side-effects, by definition, can be minimised by treating patients with the lowest effective dose and the British National Formulary (BNF: Number 33 (March 1997)) guidelines clearly differentiate between the higher doses (200-450 $\mathrm{mg}$ daily, maximum $900 \mathrm{mg}$ ) required initially to stabilise mental state, and the lower doses (150-300 mg daily) required subsequently for maintenance treatment.

We sought to determine the extent to which these guidelines were followed locally by observing the maintenance doses prescribed and whether efforts had been made to establish the lowest effective maintenance dose for each patient.

\section{The study}

All patients who had been treated with clozapine continuously for at least six months, and received their medication from Bexley Hospital pharmacy were included in the study (six months was considered to be the minimum acceptable time for a response to treatment and subsequent attempt at dosage reduction towards a minimum maintenance dose to have occurred).

The age, gender, ethnicity, duration of clozapine treatment, highest dose received and current prescribed dose were recorded for each patient. The dosage of clozapine received over time was examined for each patient and all attempts at dosage reduction recorded. The data were obtained primarily from the Clozaril Patient Monitoring Service (CPMS) pharmacy computer link, with case notes being used to complete any gaps.

\section{Findings}

Fifty-one patients had received clozapine for six months or more. Three were considered to have complied poorly with prescribed treatment (clear reference was made to this in their case notes). and inadequate information was avallable for a further four patients (old medicine cards were missing and poor documentation of doses in case notes), leaving a final study population of 44 .

Patients ranged from 21 to 62 years (mean 38 ) and 35 were male and nine female. Breakdown on the basis of ethnic origin identified 35 Caucasian, four Afro-Caribbean, three Asian and two individuals of mixed race. Patients had been prescribed clozapine for between seven and 69 months (mean 38 months).

The highest treatment dose prescribed ranged from $300 \mathrm{mg}$ to $900 \mathrm{mg}$ per day (mean $568 \mathrm{mg}$. s.d. $120 \mathrm{mg}$ ), with half the population being stabilised on $500 \mathrm{mg}$ per day or less. Only one patient received the maximum permitted daily dose of $900 \mathrm{mg}$. Current (maintenance) doses of clozapine ranged from $150 \mathrm{mg}$ to $750 \mathrm{mg} /$ day (mean $460 \mathrm{mg}$, s.d. $104 \mathrm{mg}$. Eight (18\%) patients were prescribed maintenance doses of between 150 and $300 \mathrm{mg} /$ day (within BNF guidelines). The remaining $36(82 \%)$ received doses above the BNF recommended upper limit of $300 \mathrm{mg} /$ day. Twenty-five (57\%) patients were maintained on doses of $400-500 \mathrm{mg} /$ day.

Dosage reductions had been achieved in 29 $(66 \%)$ patients and these ranged from $25 \mathrm{mg}$ to $500 \mathrm{mg} /$ day (mean $108 \mathrm{mg}$, median $100 \mathrm{mg}$ ). No attempt at dosage reduction had been made for 
15 (34\%) patients, although three of these patients had previously been treated with clozapine and a minimum effective maintenance dose determined.

The 12 patients for whom no dosage reduction had been attempted received a mean daily dose of $512 \mathrm{mg}$ clozapine, $72 \mathrm{mg}$ higher than the 'reduced' group and $52 \mathrm{mg}$ higher than the overall study population.

\section{Comment}

The mean clozapine dose in our study was $460 \mathrm{mg} /$ day, over $50 \%$ above the upper end of the BNF recommended maintenance range. In the group of patients who had received dosage reductions, the mean maintenance dose was still above this upper limit. If the BNF recommendations are accurate, local prescribing habits are associated with considerable financial implications; prescribing at the upper limit of the recommended maintenance dosage range (300 mg/day) costs $£ 170 /$ month, compared to $\$ 260 /$ month for the average maintenance dose prescribed in our study. For the 44 patients locally, the cost differential would be over $£ 47$ 000/year, a considerable sum. Fifty per cent more patients could be treated for the same cost if BNF recommendations were followed. Treating more patients from within existing resources would have major public health implications as clozapine not only has superior efficacy and a favourable neurological side-effect profile when compared with conventional antipsychotics, it has also been shown to reduce suicidality (Meltzer \& Okayli, 1995) and aggression (Special Hospitals' Treatment Resistant Schizophrenia Research Group, 1996) and be more acceptable to patients than other treatments (Wolfson \& Paton, 1996).

Eight different prescribers were involved, so the question arises as to why they all use maintenance doses higher than those recommended in the BNF. The origins of the BNF guidelines should be considered at this point. They are derived not from double-blind randomised controlled trials, but from the manufacturer's data sheet. The information contained on the data sheet is empirical and thought to represent best clinical practice. There is no objective data to support it. The CPMS also collects dosage data via laboratory haematology request forms. Such information relies on the accurate completion of request forms and is not linked in any way to clinical outcome. The CPMS database in our sample contained many obvious discrepancies. We had to search through case notes to obtain accurate prescribing information and found that, for over two-thirds of the patients involved, the CPMS information was not in line with hospital prescription records. In some cases the difference in dose was several hundred milligrams.

Consideration of the expanding literature regarding serum clozapine levels and clinical effect (Taylor \& Duncan, 1995) is also required at this point. Serum levels above $0.35 \mathrm{mg} / 1$ are associated with optimal clinical response (Perry et al, 1991), but there would appear to be little relationship between clozapine dose and serum level. It must, therefore, follow that the clinically effective dose will vary widely between individuals.

One-third of patients in our study had not experienced any reduction in dose. It is interesting to note that this is the same proportion of patients who are considered to be nonresponders to clozapine. While it is possible that dosage reduction has simply not been considered in this group of patients, or that prescribers were unaware of the guidelines contained within the BNF, it is also possible that this patient group might have fared better with dosage increases, but dose related side-effects prevented this approach.

The BNF is considered to be a reference source with regards to 'evidence based' prescribing, but the clozapine maintenance doses quoted are open to questioning on several counts. In our sample of patients treated with clozapine for six months or more, dosage reduction from the initial treatment dose had not been attempted in one-third and over three-quarters received doses above the recommended maintenance dose quoted in the BNF. While efforts should always be made to maintain patients on the lowest possible dose of any antipsychotic. the guidelines contained within the BNF should not be accepted without question.

\section{References}

Devinsky, O., Honigfeld, G. \& Patin, J. (1991) Clozapinerelated seizures. Neurology, 41, 369-371.

Gerson. S. L. \& Meltzer. H. (1992) Mechanisms of clozapine-induced agranulocytosis. Drug Safety, 7 (suppl. 1). 17-25.

KANE. J. M. (1992) Clinical efficacy of clozapine in treatment refractory schizophrenia: an overview. British Joumal of Psychiatry. 160 (suppl. 17), 41-45.

LIEBERMAN, J. A. \& SAFreRMAN, A. Z. (1992) Clinical profle of clozapine: adverse reactions and agranulocytosis. Psychiatric Quarterly. 63, 51-70.

MELTZER, H. \& OKAYL, G. (1995) Reduction of suicidality during clozapine treatment of neuroleptic-resistant schizophrenia: impact on risk-benefit assessment. American Journal of Psychiatry. 162. 183-190.

Paton, C. \& Wolfson. P. M. (1996) Is clozapine TDM therapeutic: a naturalistic study to evaluate the relationship between clozapine serum levels and clinical effect. Journal of Pharmacy Practice. 6, 371373. 
PERRY, P. J., MILLER, D. D., ARNDT, S. V., et al (1991) Clozapine and norclozapine plasma concentrations and clinical response to treatment-refractory schizophrenic patients. American Joumal of Psychiatry. 148, 231-235.

TAYLOR, D. \& DUNCAN, D. (1995) The use of clozapine plasma levels in optimising therapy. Psychiatric Bulletin. 18. 753-755.

Speclal Hospitals Treatment Resistant SchizophrenIa RESEARCH GROUP (1996) Schizophrenia, violence. clozapine and risperidone: a review. British Journal of Psychiatry. 169 (suppl. 31), 21-30.
Wolfson, P. M. \& PATON, C. (1996) Clozapine audit: what do the patients and relatives think? Journal of Mental Health, 6. 267-273.

Bernadette Murphy, Senior Registrar in Psychiatry: Colm Long, Senior House Officer in Psychiatry: and "Carol Paton, Principal Pharmacist, Oxleas NHS Trust, Bexley Hospital, Old Bexley Lane, Bexley, Kent DA5 2BW

*Correspondence

\section{Mental Health Care in China}

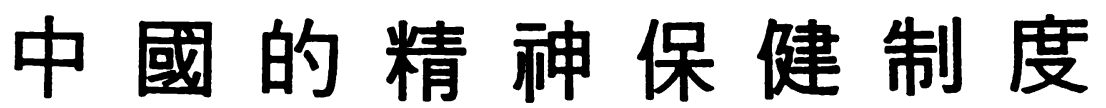

\section{State Policies, Professional Services and Family Reponsibilities by Veronica Pearson}

This book traces the development of psychiatric services in the People's Republic of China. Historical, policy and legal frameworks are constructed to provide a context in which psychiatric services may be better understood. The experience of both staff and patients in one particular hospital is examined in detail. The book raises questions about the similarities in the experience of psychiatric illness across significantly different cultures.

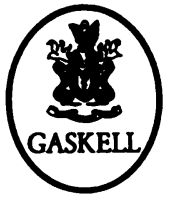

\section{£12.50 - 218pp. $\bullet 1995 \bullet$ ISBN 0902241745}

Available from bookshops and from the Publications Department, Royal College of Psychiatrists, 17 Belgrave Square,

London SW1X 8PG (Tel. 0171-235 2351, extension 146) 